\title{
Parsiyel Nefrektomi'de Cerrahi Teknik (Açık/Laparoskopik/Robotik) Önemli mi?
}

\author{
Ömer Acar ${ }^{1}$, Tarık Esen ${ }^{1,2}$
}

${ }^{1}$ Koç Üniversitesi Tıp Fakültesi, Üroloji Anabilim Dalı, İstanbul

VKV Amerikan Hastanesi, Üroloji Bölümü, İstanbul

\section{Giriş}

Son yıllarda, görüntüleme teknolojilerinde sağlanan gelişOmeler ve koruyucu hekimlik anlayışının beraberinde getirdiği proaktif uygulamalar neticesinde, tesadüfen tespit edilen küçük $(<4 \mathrm{~cm})$ böbrek kitlelerin görülme sıklığı artmıştır (1). Günümüzde, cT1a böbrek tümörlerinin cerrahi tedavisinde, teknik olarak mümkün olduğu sürece, tüm kılavuzlar tarafından parsiyel nefrektomi (PN) yapılması önerilmekte, nefron koruyucu yaklaşımın, 4 cm'den büyük ve böbrek ile sınırlı kitlesel lezyonlarda da, cerrahın tecrübesi, tümör morfometrisi, hastaya ait faktörler ve teknik yeterlilik gibi faktörler göz önüne alınmak kaydı ile uygulanabilir bir seçenek olduğu savunulmaktadır $(2,3)$.

Lokalize böbrek tümörlerinde parsiyel ve radikal nefrektomiyi karşılaştıran güncel çalışmalarda, PN'nin kronik böbrek hastalığı gelişimi ve genel sağkalım açısından daha avantajlı olduğu sonucuna varılmıştır (4-8). Parsiyel nefrektomi, bu avantajlarına rağmen ve yıllar içerisinde giderek artan bir sıklık ile yapılmaya başlanmış olmasına karşın, güncel verilere göre $4 \mathrm{~cm}$ 'in altındaki renal kitlelerin sadece \%32'sinde uygulanmaktadir (9).

$\mathrm{Bu}$ derlemede, açık, laparoskopik ve robotik PN ile ilgili güncel literatür bilgisi özetlenecektir. Özellikle; parsiyel nefrektomi uygulamasındaki güncel trendler ve perioperatif, fonksiyonel, onkolojik sonuçlar irdelenecektir.

\section{Parsiyel Nefrektomi Uygulamasındaki Güncel Trendler}

Genel olarak, parsiyel nefrektominin radikal nefrektomiye kıyasla teknik açıdan daha "zor" bir ameliyat olduğu kabul edilmektedir. Hollenback ve ark.'ları, lokalize böbrek tümörlerinin cerrahi tedavisinde PN uygulanma oranının zaman içerisinde gösterdiği değişimi incelediği çalışmalarında, 1988 senesinde 100.000 'de 0.21 olan PN oranının, 2002' de ancak 100.000 'de 1.6 'ya kadar yükselebildiğini tespit etmiş, beklenen artışın gerçekleşmemesinde etkili olan faktörlerin; PN'nin ileri düzeyde cerrahi eğitim gerektirmesi, cerrahın kişisel tecrübe ve becerisine göre verdiği kararlar, PN'nin daha fazla komplikasyon ile ilişkili olması ve PN'nin geri ödemesinde karşılaşılan sorunlar olduğunu belirtmiştir (10).

Son yillarda minimal invazif cerrahi tekniklerde sağlanan gelişmeler parsiyel nefrektomi uygulama trendlerini de etkilemiştir. Bu etkileşimde; laparoskopik PN'nin uzun bir öğre- nim eğrisi ile ilişkili olması, laparoskopik radikal nefrektominin ise tam tersine hızlı bir şekilde adapte edilip, etkin ve güvenilir bir yöntem olarak uygulanabilmesi ve robotik teknolojinin sağladığı avantajların (optik magnifikasyon, el bileği hareketlerinin simülasyonu, intrakorporeal sütürasyon kolaylığı vs.) birçok tecrübeli açık cerraha laparoskopik parsiyel nefrektomi basamağını atlayıp, minimal invazif cerrahiye süratli bir geçiş imkanı sunması oldukça etkili olmuştur. 2000-2011 yılları arasında Maryland bölgesinde sağlık hizmeti almış olan 14.620 hastanın verisinin incelendiği geniş çalışmada, PN oranının \%8.6'dan \%27'ye yükseldiği, minimal invazif radikal nefrektomi oranının \%15 arttığı, açık radikal nefrektomi oranının ise \%33 azaldığ görülmüş, laparoskopik PN oraninin, 2003 senesinde üniversite hastanelerinde \%8.9'luk bir oran yakalamış olmasına karşın, genel ortalamasının \%7.2' de kaldığı hesaplanmıştır. Bu çalışmada üniversite-dışı merkezlerdeki LPN oranının \%2.9 olduğu belirtilmiştir. Robotik PN, 2009'dan 2011'e kadar giderek yükselen bir oranda tercih edilmiş olup, üniversite hastanelerinde yapılan parsiyel nefrektomilerin \%47'sinin bu yolla gerçekleştirildiği tespit edilmiştir. Robotik cerrahideki bu yükselişe paralel olarak, renal ablasyonların uygulanma sıklığı 2008'de \%7.6'dan, 2011'de \%3.4'e kadar gerilemiştir. Çalışmanın belki de en dikkat çekici bulgusu ise; robotik cerrahinin, bağımsız bir değişken olarak, parsiyel nefrektomi yapılma ihtimalini anlamlı ölçüde yükselttiğinin gösterilmiş olmas1dır (OR: 9.03, CI 6.94-11.74, p<0.001) (11).

\section{Perioperatif Sonuçlar}

Günümüzde, açı ve minimal invazif PN'yi perioperatif morbidite, onkolojik sonuçlar ve fonksiyonel sonuçlar açısından karşılaştıran prospektif randomize çalışma bulunmamaktadır. Mukayeseli çalışmalardaki seçim yanlılığının, bulguların doğru bir şekilde yorumlanmasını kısıtlayan temel bir unsur olduğu dikkati çekmektedir.

Toplam 27 robotik, 15 laparoskopik ve 54 açık PN'nin karşılaştırıldığı ve tümör boyutu, nefrometri skoru ve preoperatif glomerüler filtrasyon hızının analizden önce gruplar arasında eşleştirildiği bir çalışmada ameliyat süresinin APN'de (147 dakika), LPN (195 dakika) ve RPN'ye (190 dakika) göre daha kısa olduğu tespit edilmiştir $(\mathrm{p}<0.001)$. Benzer şekilde; en kısa ortanca sıcak iskemi süresi, 12 dakika ile açık PN grubunda kaydedilmiştir (RPN: 25 dakika, LPN: 29.5 
dakika). Kan kaybı miktarı açık cerrahi grubunda $(250 \mathrm{ml})$, minimal invazif cerrahi gruplarına göre (RPN: $100 \mathrm{ml}, \mathrm{LPN}$ : $100 \mathrm{ml}$ ) daha fazla olmakla birlikte, ortanca hastanede kalış süresinin LPN ve RPN gruplarında (2'şer gün), APN grubuna göre (3 gün) daha kısa olduğu bildirilmiştir $(\mathrm{p}<0.001)$. Perioperatif komplikasyonların görülme sıklı̆̆1 ise gruplar arasında anlamlı farklılık sergilememiştir (12).

Minimal invazif cerrahide tecrübeli üç farklı cerrahın gerçekleştirdiği 118 ardışık LPN ve 129 ardışık RPN'nin karşılaştırıldığ endeksi, yaş, cinsiyet ve tümör boyutu açısından fark bulunmayan bir diğer retrospektif çalışmada ise; laparoskopik ve robotik PN'de kaydedilen ortalama ameliyat süresi (RPN: 189 dakika, LPN: 174 dakika), patolojik tümör boyutu (RPN: $2.8 \mathrm{~cm}$, LPN: $2.5 \mathrm{~cm}$ ) ve cerrahi sınır pozitifliği oranları (RPN: \%3.9, LPN: \%1) birbirine benzer bulunmuştur. Robotik PN lehine elde edilen bulgular ise; daha az intraoperatif kan kaybı (155 vs 196 ml, p=0.03), daha kısa süreli hospitalizasyon (2.4 vs 2.7 gün, $\mathrm{p}<0.0001)$ ve daha kısa sıcak iskemi süresi (19.7 vs $28.4 \mathrm{~min}, \mathrm{p}<0.0001)$ olmuştur. Robotik PN grubun- da, tümör kompleksitesinin ameliyat süresi ve kan kaybı miktarına etkisi olmadığı sonucuna varılırken; LPN grubunda bu iki parametrenin olumsuz morfometrik özelliklerden anlamlı düzeyde etkilendiği tespit edilmiştir. Major ve minör komplikasyonlar açısından gruplar arasında anlamlı farklılık saptanmayan bu çalışmada, RPN grubunda 3 hastada, LPN grubunda ise 4 hastada idrar ekstravazasyonu geliştiği bildirilmiştir. Cerrahi sınırda fokal mikroskopik pozitiflik oranları RPN grubunda \%3.9, LPN grubunda ise \%0.8 olarak kaydedilmiştir (13). Robotik ve laparoskopik PN'yi karşılaştıran güncel çalışmalarda elde edilen perioperatif sonuçlar Tablo 1'de özetlenmiştir (13-19).

Simhan ve ark., R.E.N.A.L. nefrometri skoruna göre orta ve yüksek derecede komplike tümörler için uygulanmış olan 81 RPN ve 136 APN'yi karşılaştırdıkları retrospektif çalışmalarında, patolojik evre'nin ve tümör çapının $(3.2$ vs. $4.1 \mathrm{~cm}$, $\mathrm{p}<0.0001)$ APN grubunda daha yüksek olduğu tespitinde bulunmuşlardır. Gruplar arasında GFR'deki perioperatif değişim açısından anlamlı farklılık saptanmaz iken; orta derecede komplike tümörlerde RPN'nin daha uzun ameliyat

Tablo 1: Karşılaştırmalı robotik ve laparoskopik parsiyel nefrektomi serilerinde elde edilen perioperatif sonuçlar

\begin{tabular}{lccccccc}
\hline Çalışma & $\begin{array}{c}\text { N, } \\
\text { LPN/RPN }\end{array}$ & $\begin{array}{c}\text { Ameliyat } \\
\text { süresi (dk) } \\
\text { LPN/RPN }\end{array}$ & $\begin{array}{c}\text { Tahmini Kan } \\
\text { Kaybi miktarı } \\
(\mathbf{m l}) \\
\text { LPN/RPN }\end{array}$ & $\begin{array}{c}\text { Transfüzyon } \\
\text { oranı (n) } \\
\text { LPN/RPN }\end{array}$ & $\begin{array}{c}\text { Sicak iskemi } \\
\text { süresi (dk) } \\
\text { LPN/ RPN }\end{array}$ & $\begin{array}{c}\text { Komplikasyonlar } \\
\text { (n) } \\
\text { LPN/RPN }\end{array}$ & $\begin{array}{c}\text { Hastanede } \\
\text { kalış süresi } \\
\text { (gün) } \\
\text { LPN/RPN }\end{array}$ \\
\hline Benway ve ark. 2009 (13) & $118 / 129$ & $174 / 189$ & $196 / 155$ & $2 / 1$ & $28.4 / 19.7$ & $12 / 11$ \\
Jeongve ark. 2009 (14) & $26 / 31$ & $139 / 169$ & $208 / 198$ & $1 / 1$ & $17 / 20$ & NA & $2.7 / 2.4$ \\
Williams ve ark. 2011 (15) & $59 / 27$ & $221 / 233$ & $146.3 / 179.6$ & NA & $18.5 / 28.0$ & NA & $2.71 / 2.51$ \\
Ellison ve ark. 2012 (16) & $108 / 108$ & $162 / 215$ & $400 / 368$ & NA & $19.3 / 24.9$ & NA & $2.2 / 2.7$ \\
Pierorazio ve ark. 2011 (17) & $102 / 48$ & $192 / 152$ & $245.1 / 122.4$ & NA & $18 / 14.1$ & NA & NA \\
Wang ve ark. 2009 (18) & $62 / 40$ & $156 / 140$ & $173 / 136$ & $1 / 2$ & $25 / 19$ & $8 / 6$ & $2.9 / 2.5$ \\
Long ve ark. 2012 (19) & $182 / 199$ & $240.7 / 196.9$ & $325.0 / 280.2$ & $\% 14.3 / \% 12.1$ & $23.2 / 22.4$ & $\% 5.5 / \% 3.0$ & $1.36 / 2.21$ \\
\hline
\end{tabular}

Tablo 2: Karşılaştırmalı robotik ve açık parsiyel nefrektomi serilerinde elde edilen perioperatif sonuçlar

\begin{tabular}{|c|c|c|c|c|c|c|c|}
\hline Çalışma & $\begin{array}{c}\text { N, } \\
\text { RPN/APN }\end{array}$ & $\begin{array}{c}\text { Ameliyat } \\
\text { süresi (dk) } \\
\text { RPN/APN }\end{array}$ & $\begin{array}{c}\text { Tahmini Kan } \\
\text { Kaybı miktarı } \\
(\mathrm{ml}) \\
\text { RPN/APN }\end{array}$ & $\begin{array}{c}\text { Transfüzyon } \\
\text { oranı (n) } \\
\text { RPN/APN }\end{array}$ & $\begin{array}{l}\text { Sicak iskemi } \\
\text { süresi (dk) } \\
\text { RPN/APN }\end{array}$ & $\begin{array}{c}\text { Komplikasyonlar } \\
\text { (n) } \\
\text { RPN/APN }\end{array}$ & $\begin{array}{c}\text { Hastanede } \\
\text { kalış süresi } \\
\text { (gün) } \\
\text { RPN/APN }\end{array}$ \\
\hline $\begin{array}{l}\text { Alemozaffar } \\
\text { ve ark. } 2013(21)\end{array}$ & $25 / 25$ & $231.8 / 238.3$ & $178 / 275$ & NA & NA & NA & $2.5 / 4.6$ \\
\hline Lee ve ark. 2011 (22) & $69 / 234$ & $192.4 / 142.8$ & $228.7 / 216.5$ & $3 / 11$ & $23 / 18.9$ & $9 / 46$ & $6.2 / 8.9$ \\
\hline $\begin{array}{l}\text { Masson-Lecomte } \\
\text { ve ark. } 2013 \text { (23) }\end{array}$ & $42 / 58$ & $222.7 / 128.4$ & $142.9 / 414.7$ & $2 / 4$ & $17.5 / 17.1$ & $4 / 8$ & $3.8 / 6.8$ \\
\hline $\begin{array}{l}\text { Minervini } \\
\text { ve ark. } 2013 \text { (24) }\end{array}$ & $105 / 198$ & $168 / 123$ & $125 / 230$ & $4 / 21$ & $18.2 / 18.7$ & $12 / 58$ & NA \\
\hline $\begin{array}{l}\text { Simhan ve ark. 2012, } \\
\text { Yüksek kompleksite } \\
\text { grubu (20) }\end{array}$ & $10 / 54$ & 221.1/197.5 & $225 / 330.6$ & NA & $33.8 / 28.8$ & $37 / 103$ & $2.9 / 6.1$ \\
\hline $\begin{array}{l}\text { Simhanve ark. 2012, } \\
\text { Orta kompleksite } \\
\text { grubu (20) }\end{array}$ & $81 / 136$ & 205.9/189.5 & $131.3 / 256.5$ & NA & $29.4 / 29.4$ & $37 / 103$ & $3.7 / 5.6$ \\
\hline Yu ve ark. 2012 (25) & $253 / 1769$ & NA & NA & $20 / 137$ & NA & $46 / 512$ & $2.8 / 4.5$ \\
\hline Esen ve ark. 2015 & $59 / 74$ & $143.7 / 101$ & 201.1/187.2 & $3 / 4$ & $22.3 / 16.7$ & $13 / 18$ & $3.8 / 4.3$ \\
\hline
\end{tabular}


süresi (205.9 vs. 189.5 dakika), daha az kan kaybı (131.1 vs. $256.5 \mathrm{ml}$ ) ve daha kısa süreli hospitalizasyon (3.7 vs. 5.6 gün) ile ilişki olduğu sonucuna varılmıştır. Hastanede kalış süresi için robotik cerrahinin sağladığı avantajın yüksek derecede komplike tümörler için de geçerli olduğu belirtilmiştir. Komplikasyon ve cerrahi sınır pozitifliği oranlarının ise gruplar arasında benzer olduğu vurgulanmıştır (20). Kliniğimizde, robotik cerrahi için gerekli altyapı oluşturulduktan sonra (Mayıs 2010 - Aralık 2014) gerçekleştirilen 133 PN'nin perioperatif, onkolojik ve fonksiyonel sonuçlar aç1sından karşılaştıııldığı çalışmada da, açık $(n=74)$ ve robotik $(n=59)$ PN grupları arasındaki tek anlamlı farklılı̆ın, robotik PN lehine daha kısa olan hastanede kalış süresi olduğu tespit edilmiştir (henüz yayınlanmamış bilgi). Robotik ve açik PN'yi karşılaştıran güncel çalışmalarda elde edilen perioperatif sonuçlar Tablo 2'de özetlenmiştir (20-25).

Aboumarzouk ve ark.ları'nın, 2000-2012 yılları arasında yayınlanmış olan RPN-LPN karşılaştırmalı çalışmaları ele aldıkları güncel bir meta-analizde; hasta yaşı, cinsiyet, tümör boyutu, tümör lokalizasyonu ve malignite saptanma oranları arasında anlamlı farklılık tespit edilmemiştir. Benzer şekilde; ameliyat süresi, tahmini kan kaybı miktarı, açığa dönüş oranı, komplikasyonlar, cerrahi sınır pozitifliği oranı ve hastanede kalış süresi gruplar arasında benzer değerler sergilemiştir. Aradaki tek anlamlı farklılığın, robotik PN'de, laparoskopik PN'ye kıyasla daha kısa olan sıcak iskemi süresi $(\mathrm{p}=0.0008)$ olduğu sonucuna varılmıştır (26).

Nispeten daha yeni bir teknik olmasına karşın RPN'nin; perioperatif sonuçlar, komplikasyon oranları ve cerrahi sınır pozitifliği açısından LPN ve APN'ye benzer bir performans sergilediği dikkati çekmektedir. Ancak yine de, açık ve minimal invazif yaklaşımların, perioperatif sonuçlar dikkate alındığında, birbirlerine kaydadeğer bir üstünlük sağlayamadıkları söylenebilir.

\section{Fonksiyonel sonuçlar}

Güncel çalışmalarda, uzamış sıcak iskemi süresi ve de-novo renal disfonksiyon gelişimi arasında anlamlı bir ilişki olduğu dikkati çekmektedir. Thompson ve ark.'ları, soliter böbrekte kitle sebebiyle açık ya da laparoskopik PN yapılmış olan 362 hastayı değerlendirdikleri çalışmalarında, sıcak iskemi süresindeki her 1 dakikalık artışın, akut böbrek yetersizliği riskini 1.05 kat arttırdığını raporlamışlar ve ayrıca, sıcak iskemi süresi ile postoperatif de-novo evre 4 kronik böbrek hastalığı gelişimi arasında anlamlı ilişki kurmuşlardır (27). Elde edilen diğer önemli sonuçlar ise; bu bulguların preoperatif unsurlara (GFR, tümör çapı, cerrahi teknik) göre kontrollü bir analiz yapıldığı zaman da geçerli olması ve akut böbrek yetersizliği ve de-novo evre 4 kronik böbrek yetersizliği gelişimi açısından kritik sıcak iskemi süresinin 25 dakika olduğudur $(27,28)$. Bu tespit, ortalama sıcak iskemi süresi, minimal invazif yaklaşımlardan genel olarak daha kısa olan açı $\mathrm{PN}^{\prime}$ yi renal fonksiyonun optimizasyonu açısından ön plana çıarmaktadır (29).

Diğer gruplar ise, cerrahi yaklaşım tercihi ne olursa olsun, sıcak iskemi süresinin 20 dakika ile, soğuk iskemi süresinin ise 30-35 dakika ile sinırlandırılması gerektiğini savunmuşlardır (27-30). Laparoskopik ve açık PN'nin uzun dönem (10 yıl) fonksiyonel sonuçlarını değerlendiren güncel bir çalışmada, Lane ve ark.'ları, ortanca GFR'nin LPN grubunda \%16.9, APN grubunda ise \%14 gerilediğini saptamış- lardır $(\mathrm{p}=0.5)$. Aradaki fark anlamlı olmasa da; beklenildiği üzere, sıcak iskemi süresi arttıkça GFR'deki düşüşün de belirginleştiği bildirilmiştir (30).

Maksimum tolere edilebilir sıcak iskemi süresi için evrensel olarak kabul görmüş bir standart olmasa da, parsiyel nefrektomiden sonra gelişebilecek kronik böbrek hastalığının önüne geçebilmek için, teknik olarak mümkün ise cerrahiyi pedikülü klempe etmeden tamamlamak gerekmektedir. Ancak bu her zaman mümkün olamayacağı için, minimal invazif parsiyel nefrektomide sıcak iskemi süresini kısaltıp, renal fonksiyonları optimize edebilmek üzere bazı teknik modifikasyonlar [devamlı sütür tekniği (31), ihtiyaca göre pedikül klempleme (32), erken deklempaj (29), kayan klipler ile renorafi (33), segmental arterlerin klemplenmesi (34) ve sıfır-iskemi tekniği (35)] gündeme getirilmiştir. Kliniğimizde robotik teknoloji kullanılmaya başladıktan sonra, aynı tecrübeli açı cerrah tarafından gerçekleştirilen ilk 44 robotik PN'nin değerlendirildiği ve ortalama takip süresinin 18.9 ay olduğu çalışmada, aralarında hasta yaşı, tümör çapı ve R.E.N.A.L. skor açısından fark bulunmayan iskemik (ortalama sıcak iskemi süresi: 22.5 dakika) ve non-iskemik (pedikül hiç klempe edilmeden) robotik PN grupları karşılaştırılmıştır. Sonuç olarak; ameliyat süresi, tahmini kan kaybı miktarı, hospitalizasyon süresi, perioperatif morbidite, açı̆̆a dönüş oranı, cerrahi sınır pozitiflik oranı ve eGFR'deki perioperatif değişim açısından gruplar arasında anlamlı farklılık olmadığ saptanmıştır. Öğrenme eğrisinin ilk döneminde olmasına karşın, gruplarda benzer bulgular elde edilmiş olması; tecrübeli açlk cerrahların robotik PN'yi daha kolay ve hızlı bir şekilde adapte edebilmesi ve robotik altyapının rekonstrüktif işlemlerde cerraha sunduğu avantajlar ile ilişkilendirilmiştir (36).

Tümör kompleksitesini standart ve objektif bir şekilde ifade etmek için kullanılan morfometrik skorlama sistemleri (R.E.N.A.L. nefrometri skoru, P.A.D.U.A. skoru ve C-indeks) sıcak iskemi süresini öngörebilmek için kullanılabilir (37-39). Genel olarak, tümör kompleksitesi arttıkça, daha çok açık ve mümkünse sıcak iskemi altında nefron koruyucu cerrahi uygulama yönünde bir eğilim mevcuttur. Kliniğimizde 2 yıllık bir zaman dilimi içerisinde gerçekleştirilen açı ve robotik PN'lerin ele alındığ 55 hastalık (32 robotik, 23 açık) çalışmada da, bu eğilimi destekler şekilde, robotik PN uygulanan kitlelerin, açık PN tercih edilmiş olan kitlelere göre genel olarak daha olumlu bir morfometrik profile sahip olduğu sonucuna varılmıştır. Cerrahi yaklaşım tercihi ve cerrahinin gerçekleştirildiği koşullara göre oluşturulan alt gruplar (açı-iskemik vs. açık-noniskemik vs. robotik-iskemik vs. robotik-noniskemik) karşılaştırıldığında, açık-iskemik PN grubundaki ortalama R.E.N.A.L. skor ve P.A.D.U.A. skorun diğer alt gruplarda ölçülen ortalama değerlerden anlamlı ölçüde daha yüksek olduğu kaydedilmiştir. Bu çalışmada elde edilen bir diğer önemli bulgu ise, artan tümör kompleksitesinin açık cerrahi yaklaşım tercihini belirleyen bir unsur olduğu ve belli eşik değerler üzerinde (R.E.N.A.L. skor için 6.5, P.A.D.U.A. skor için 7.5) bu belirleyiciliğin istatistiksel anlam kazandığıdır (40).

Ancak, tecrübeli minimal invazif cerrahlar, çok komplike tümörleri (soliter böbrekte kitle, hiler ve/veya endofitik yerleşim gösteren kitle), laparoskopik ya da robotik yaklaşım ile, iskemi süresini kısttlayarak, etkin ve güvenilir bir şekilde tedavi edebilmektedir (41). Gill ve ark., hiler kitleler için yaptıkları 25 vakalık laparoskopik PN serilerinde, ortalama sicak 
iskemi süresini 36.4 dakika olarak bildirmiştir (42). Bunun aksine, hiler kitlelerde robotik PN'nin başarısını inceleyen retrospektif, çok merkezli bir çalışmada ortalama sıcak iskemi süresi 26.3 dakika olarak hesaplanmıştır (43). Üç boyutlu görüntü ve intrakorporeal sütürasyon kolaylığı sıcak iskemi süresindeki göreceli azalmanın temel sebepleri olarak vurgulanmıştır. Toplam 41 hasta içeren bu çalışmada, bir hastada ürinom geliştiği ve diğer bir hastada ise kan transfüzyonu gerektiği rapor edilmişir. Cerrahi sınır pozitifliği oranının $\% 2.4(n=1)$ olduğu bu seride, perioperatif renal fonksiyonel değişim hakkında bilgi sunulmamıştır.

\section{Onkolojik Sonuçlar}

Literatürde; açı ve minimal invazif $\mathrm{PN}^{\prime}$ yi, onkolojik sonuçlara odaklanarak birbirleri ile kıyaslayan, uzun takip süresine ve yeterli hasta sayısına sahip çalışma sayısı oldukça kısıtlıdır. Soliter cT1 renal kitle sebebiyle, 1999-2007 yılları arasında açık ya da laparoskopik PN yapılmış olan ve en az 5 yıllık takip bilgisi bulunan 1541 hastayı içeren bir çalışmada, cerrahi yaklaşım tercihinin (açık vs. laparoskopik), genel mortalite oranını ve metastaz gelişme riskini etkileyen bir unsur olmadığı bildirilmiştir. Açık ve laparoskopik PN'nin 10 yıllık onkolojik sonuçlar açısından benzer bulunduğu bu çalışmada, cerrahi yaklaşım tercihini belirleyen temel unsurlar olarak; cerrahın tecrübesi, hastaya ait faktörler ve tümöre ait özellikler vurgulanmıştır (30). Springer ve ark.ları'nın, tesadüfen tespit edilmiş cT1 $(<7 \mathrm{~cm})$ böbrek tümörü sebebiyle laparoskopik ya da açı $\mathrm{PN}$ yaptıkları ve yaş, cinsiyet, vücut kitle endeksi, A.S.A. skoru, R.E.N.A.L. nefrometri skoru gibi klinik parametrelerin gruplar arasinda anlamlı farklılık sergilemediği, 340 hastalık retrospektif çalışmada, 5 yıllık genel ve kansere özgü sağkalım oranları LPN ve APN gruplarinda sirasiyla $\% 94, \% 91$ ve $\% 92, \% 88$ olarak hesaplanmiştır (44).

Khalifeh ve ark.ları'nın, 2006-2013 yılları arasında robotik PN yaptıkları ve en az 2 yıllık takip verisi bulunan 427 hastanın sonuçlarını değerlendirdikleri çalışmada, 5 yıllık genel ve kansere özgü sağkalım oranları sırasıyla, \%90.2 ve \%98.2 olarak hesaplanmıştır (45). Benzer şekilde, Mukkamala ve ark.ları, 1998 ve 2011 yılları arasında böbrekte kitle nedeniyle laparoskopik veya robotik PN yapılmış olan ve ortalama 3 yıllık takip bilgisi bulunan 417 hastalık çalışmalarında, 2, 5 ve 10 yıllık genel sağkalım oranlarını sırasıyla, \%95.6, \%89.1 ve \%70.7 olarak bildirmiştir. Aynı zaman aralıklarındaki nükssüz sağkalım oranları ise sırasıyla \%98.2, \%93.5 ve $\% 88.3$ olarak hesaplanmıştır (46).

Mevcut literatürdeki verilere dayanarak; cT1 böbrek tümörleri için açık ve minimal invazif PN arasında onkolojik sonuçlar açısından anlamlı farklılık bulunmadığı söylenebilir. Ancak yine de, bu teknikler prospektif, randomize, kontrollü çalışmalar kapsamında uzun vadede elde edilen sonuçlar açısından karşılaştııılmadan net yorum yapmak mümkün değildir.

\section{Sonuç}

Parsiyel nefrektomi'nin uygulanış şekli elde edilecek sonuçlar açısından oldukça önemli bir unsurdur. Ancak, onkolojik ve fonksiyonel açıdan, açı ve minimal invazif yöntemler arasında bugüne kadar kantlanabilmiş anlamlı bir farklılık mevcut değildir. Robotik PN'den sonraki postopera- tif sürecin biraz daha kısa sürdüğ̈̈ ve belki de hasta açısından biraz daha konforlu geçtiği sonucuna varılabilir. Yine de, mevcut literatür bilgisi parsiyel nefrektominin uygulanış şeklini, herhangi bir tekniği diğerlerinden çok farklı kılarak, değiştirebilecek netlikte ve kuvvette değildir.

Halen, parsiyel nefrektomi adayı bir hastanin tedavi yaklaşımı hakkında karar verilirken; cerrahın tecrübe düzeyi, hastaya ait özellikler, tümörün çapı, tümörün kompleksitesi, hastanenin sahip olduğu teknolojik donanım ve maddi faktörler belirleyici olmaktadır. Parsiyel nefrektomi'nin hangi şekilde yapılacağından daha önemlisi, teknik olarak mümkün olduğu halde minimal invaziflik uğruna nefron koruyucu yaklaşımdan vazgeçilmemesidir.

\section{Kaynaklar}

1. Kane CJ, Mallin K, Ritchey J, Cooperberg MR, Carroll PR. Renal cell cancer stage migration: analysis of the National Cancer Data Base. Cancer 2008; 113: 78-83.

2. Motzer RJ, Agarwal N, Beard C, Bolger GB, Boston B, Carducci MA, Choueiri TK, Figlin RA, Fishman M, Hancock SL, Hudes GR, Jonasch E, Kessinger A, Kuzel TM, Lange PH, Levine EG, Margolin KA, Michaelson MD, Olencki T, Pili R, Redman BG, Robertson CN, Schwartz LH, Sheinfeld J, Wang J. NCCN clinical practice guidelines in oncology: kidney cancer. J Natl Compr Canc Netw 2009; 7: 618-630.

3. Ljungberg B, Cowan NC, Hanbury DC, Hora M, Kuczyk MA, Merseburger AS, Patard JJ, Mulders PF, Sinescu IC; European Association of Urology Guideline Group. EAU guidelines on renal cell carcinoma: the 2010 update. Eur Urol 2010; 58: 398-406.

4. Huang WC, Elkin EB, Levey AS, Jang TL, Russo P. Partial nephrectomy versus radical nephrectomy in patients with small renal tumors--is there a difference in mortality and cardiovascular outcomes? J Urol 2009; 181: 55-61; discussion 61-62.

5. Huang WC, Levey AS, Serio AM, Snyder M, Vickers AJ, Raj GV, Scardino PT, Russo P. Chronic kidney disease after nephrectomy in patients with renal cortical tumours: a retrospective cohort study. Lancet Oncol 2006; 7: 735740.

6. Miller DC, Schonlau M, Litwin MS, Lai J, Saigal CS; Urologic Diseases in America Project. Renal and cardiovascular morbidity after partial or radical nephrectomy. Cancer 2008; 112: 511-520.

7. Thompson RH, Boorjian SA, Lohse CM, Leibovich BC, Kwon ED, Cheville JC, Blute ML. Radical nephrectomy for pT1a renal masses may be associated with decreased overall survival compared with partial nephrectomy. J Urol 2008; 179: 468-471; discussion 472-473.

8. Thompson RH, Siddiqui S, Lohse CM, Leibovich BC, Russo P, Blute ML. Partial versus radical nephrectomy for 4 to $7 \mathrm{~cm}$ renal cortical tumors. J Urol 2009; 182: 26012606.

9. Cooperberg MR, Mallin K, Kane CJ, Carroll PR. Treatment trends for stage I renal cell carcinoma. J Urol 2011; 186: 394-399.

10. Hollenbeck BK, Taub DA, Miller DC, Dunn RL, Wei JT. National utilization trends of partial nephrectomy for renal cell carcinoma: a case of underutilization? Urology 2006; 67: 254-9. 
11. Patel HD, Mullins JK, Pierorazio PM, Jayram G, Cohen JE, Matlaga BR, Allaf ME. Trends in renal surgery: robotic technology is associated with increased use of partial nephrectomy. J Urol 2013; 189: 1229-1235.

12. Lucas SM, Mellon MJ, Erntsberger L, Sundaram CP. A comparison of robotic, laparoscopic and open partial nephrectomy. JSLS 2012; 16: 581-587.

13. Benway BM, Bhayani SB, Rogers CG, Dulabon LM, Patel MN, Lipkin M, Wang AJ, Stifelman MD. Robot assisted partial nephrectomy versus laparoscopic partial nephrectomy for renal tumors: a multi-institutional analysis of perioperative outcomes. J Urol 2009; 182: 866872.

14. Jeong W, Park SY, Lorenzo EI, Oh CK, Han WK, Rha KH. Laparoscopic partial nephrectomy versus robot-assisted laparoscopic partial nephrectomy. J Endourol 2009; 23: 1457-1460.

15. Williams SB, Kacker R, Alemozaffar M, Francisco IS, Mechaber J, Wagner AA. Robotic partial nephrectomy versus laparoscopic partial nephrectomy: a single laparoscopic trained surgeon's experience in the development of a robotic partial nephrectomy program. World J Urol 2013; 31: 793-798.

16. Ellison JS, Montgomery JS, Wolf JS Jr, Hafez KS, Miller DC, Weizer AZ. A matched comparison of perioperative outcomes of a single laparoscopic surgeon versus a multisurgeon robot-assisted cohort for partial nephrectomy. J Urol 2012; 188: 45-50.

17. Pierorazio PM, Patel HD, Feng T, Yohannan J, Hyams ES, Allaf ME. Robotic-assisted versus traditional laparoscopic partial nephrectomy: comparison of outcomes and evaluation of learning curve. Urology 2011; 78: 813-819.

18. Wang AJ, Bhayani SB. Robotic partial nephrectomy versus laparoscopic partial nephrectomy for renal cell carcinoma: single-surgeon analysis of $>100$ consecutive procedures. Urology 2009; 73: 306-310.

19. Long JA, Yakoubi R, Lee B, Guillotreau J, Autorino R, Laydner H, Eyraud R, Stein RJ, Kaouk JH, Haber GP. Robotic versus laparoscopic partial nephrectomy for complex tumors: comparison of perioperative outcomes. Eur Urol 2012; 61: 1257-1262.

20. Simhan J, Smaldone MC, Tsai KJ, Li T, Reyes JM, Canter D, Kutikov A, Chen DY, Greenberg RE, Uzzo RG, Viterbo R. Perioperative outcomes of robotic and open partial nephrectomy for moderately and highly complex renal lesions. J Urol 2012; 187: 2000-2004.

21. Alemozaffar M, Chang SL, Kacker R, Sun M, DeWolf WC, Wagner AA. Comparing costs of robotic, laparoscopic, and open partial nephrectomy. J Endourol 2013; 27: 560565.

22. Lee S, Oh J, Hong SK, Lee SE, Byun SS. Open versus robot-assisted partial nephrectomy: effect on clinical outcome. J Endourol 2011; 25: 1181-1185.

23. Masson-Lecomte A, Yates DR, Hupertan V, Haertig A, Chartier-Kastler E, Bitker MO, Vaessen C, Rouprêt M. A prospective comparison of the pathologic and surgical outcomes obtained after elective treatment of renal cell carcinoma by open or robot-assisted partial nephrectomy. Urol Oncol 2013; 31: 924-929.

24. Minervini A, Vittori G, Antonelli A, Celia A, Crivellaro S, Dente D, Di Santo V, Frea B, Gacci M, Gritti A, Masieri L, Morlacco A, Porreca A, Rocco B, Parma P, Simeone C,
Zaramella S, Carini M, Serni S. Open versus roboticassisted partial nephrectomy: a multicenter comparison study of perioperative results and complications. World J Urol 2014; 32: 287-293.

25. Yu HY, Hevelone ND, Lipsitz SR, Kowalczyk KJ, Hu JC. Use, costs and comparative effectiveness of robotic assisted, laparoscopic and open urological surgery. J Urol 2012; 187: 1392-1398.

26. Aboumarzouk OM, Stein RJ, Eyraud R, Haber GP, Chlosta PL, Somani BK, Kaouk JH. Robotic versus laparoscopic partial nephrectomy: a systematic review and meta-analysis. Eur Urol 2012; 62: 1023-1033.

27. Thompson RH, Lane BR, Lohse CM, Leibovich BC, Fergany A, Frank I, Gill IS, Blute ML, Campbell SC. Every minute counts when the renal hilum is clamped during partial nephrectomy. Eur Urol 2010; 58: 340-345.

28. Thompson RH, Lane BR, Lohse CM, Leibovich BC, Fergany A, Frank I, Gill IS, Campbell SC, Blute ML. Comparison of warm ischemia versus no ischemia during partial nephrectomy on a solitary kidney. Eur Urol 2010; 58: 331-336.

29. Nguyen MM, Gill IS. Halving ischemia time during laparoscopic partial nephrectomy. J Urol 2008; 179: 627632.

30. Lane BR, Campbell SC, Gill IS. 10-year oncologic outcomes after laparoscopic and open partial nephrectomy. J Urol 2013; 190: 44-49.

31. Baumert H, Ballaro A, Shah N, Mansouri D, Zafar N, Molinié V, Neal D. Reducing warm ischaemia time during laparoscopic partial nephrectomy: a prospective comparison of two renal closure techniques. Eur Urol 2007; 52: 1164-1169.

32. Bollens R, Rosenblatt A, Espinoza BP, De Groote A, Quackels T, Roumeguere T, Vanden Bossche M, Wespes E, Zlotta AR, Schulman CC. Laparoscopic partial nephrectomy with "on-demand" clamping reduces warm ischemia time. Eur Urol 2007; 52: 804-809.

33. Benway BM, Wang AJ, Cabello JM, Bhayani SB. Robotic partial nephrectomy with sliding-clip renorrhaphy: technique and outcomes. Eur Urol 2009; 55: 592-599.

34. Shao P, Qin C, Yin C, Meng X, Ju X, Li J, Lv Q, Zhang W, $\mathrm{Xu} Z$ Z. Laparoscopic partial nephrectomy with segmental renal artery clamping: technique and clinical outcomes. Eur Urol 2011; 59: 849-855.

35. Gill IS, Eisenberg MS, Aron M, Berger A, Ukimura O, Patil MB, Campese V, Thangathurai D, Desai MM. "Zero ischemia" partial nephrectomy: novel laparoscopic and robotic technique. Eur Urol 2011; 59: 128-134.

36. Acar Ö, Esen T, Musaoğlu A, Vural M. Do we need to clamp the renal hilum liberally during the initial phase of the learning curve of robot-assisted nephron-sparing surgery? ScientificWorldJournal. 2014; 498917.

37. Hew MN, Baseskioglu B, Barwari K, Axwijk PH, Can C, Horenblas S, Bex A, Rosette JJ, Pes MP. Critical appraisal of the PADUA classification and assessment of the R.E.N.A.L. nephrometry score in patients undergoing partial nephrectomy. J Urol 2011; 186: 42-46.

38. Waldert M, Waalkes S, Klatte T, Kuczyk MA, Weibl P, Schüller G, Merseburger AS, Remzi M. External validation of the preoperative anatomical classification for prediction of complications related to nephron-sparing surgery. World J Urol 2010; 28: 531-535. 
39. Ficarra V, Bhayani S, Porter J, Buffi N, Lee R, Cestari A, Mottrie A. Predictors of warm ischemia time and perioperative complications in a multicenter, international series of robot-assisted partial nephrectomy. Eur Urol 2012; 61: 395-402.

40. Esen T, Acar Ö, Musaoğlu A, Vural M. Morphometric profile of the localized renal tumors managed either by open or robot-assisted nephron-sparing surgery: the impact of scoring systems on the decision making process. BMC Urol 2013; 13: 63.

41. Kim EH, Tanagho YS, Sandhu GS, Bhayani SB, Figenshau RS. Off-clamp robot-assisted partial nephrectomy for complex renal tumors. J Endourol 2012; 26: 1177-1182.

42. Gill IS, Colombo JR Jr, Frank I, Moinzadeh A, Kaouk J, Desai M. Laparoscopic partial nephrectomy for hilar tumors. J Urol 2005; 174: 850-853.

43. Dulabon LM, Kaouk JH, Haber GP, Berkman DS, Rogers CG, Petros F, Bhayani SB, Stifelman MD. Multiinstitutional analysis of robotic partial nephrectomy for hilar versus nonhilar lesions in 446 consecutive cases. Eur Urol 2011; 59: 325-330.
44. Springer C, Hoda MR, Fajkovic H, Pini G, Mohammed N, Fornara P, Greco F. Laparoscopic vs open partial nephrectomy for T1 renal tumours: evaluation of longterm oncological and functional outcomes in 340 patients. BJU Int 2013; 111: 281-288.

45. Khalifeh A, Autorino R, Eyraud R, Samarasekera D, Laydner H, Panumatrassamee K, Stein RJ, Kaouk JH. Three-year oncologic and renal functional outcomes after robot-assisted partial nephrectomy. Eur Urol 2013; 64: 744-750.

46. Mukkamala A, He C, Weizer AZ, Hafez KS, Miller DC, Montgomery JS, Wolf JS Jr. Long-term oncologic outcomes of minimally invasive partial nephrectomy for renal-cell carcinoma. J Endourol 2014; 28: 649-654.

\section{Yazışma Adresi:}

Tarık Esen

Koç Üniversitesi, Tıp Fakültesi, Üroloji Anabilim Dalı, İstanbul Tel: +90 5323623452

e-mail: tarikesen@doruk.net.tr 